\title{
RURAL URBAN MIGRATION AND WOMEN IN URBAN SLUMS OF KARACHI
}

\author{
Shagufta Nasreen ${ }^{*}$ \\ Asma Manzoor ${ }^{* *}$
}

\begin{abstract}
Poverty creates many problems. Out of which one major problem is an increase in migration rate. In Pakistan, the rate of inter province and rural urban migration has increased in the last few years resulting in an expansion in urban population. The objective of this study was to explore the experience of women who have migrated from rural to urban areas with their families and are living in urban slums. Moreover, the study aims to explore the reasons of migration from rural to urban areas, the change occurred in their living conditions and their level of satisfaction. Total 100 women from selected katchi abadis (urban slums) of Karachi and were in-depth interviewed through questionnaire method. To have an in depth analysis of the situation, both open and closed ended questions were included. Results show that most of these women have migrated with their families due to poverty. The need is to take decisions that promote equity and social justice. The distribution of resources and development planning need to focus on the need of urban and rural areas on equal bases because just moving towards metropolitan city does not change their living rather it is deteriorating the situation.
\end{abstract}

Keywords: Rural urban migration, poverty, gender, women

\section{Introduction}

In many developing countries, urbanization is increasing not only due to natural increase in urban population but also by an enormous influx of migrants from rural areas. Internal migration especially rural-urban migration has become an important area of concern in policy and research. Increasing urbanization, stimulated by rural-urban migration is showing a remarkable influx of migrants in big cities such as Karachi. Usually low skilled and low waged workers voluntarily move from rural to urban areas for better quality of life.

The internal migration of people due to work etc. is not new. However, there is certain powerful evidence which shows that during the last two decades inhabitants' mobility rate has increased extraordinarily from different places across Asia. In 2010, the AsiaPacific region urban population amounted to 754 million people, which is more than the combined population of the United States of America and the European Union. Seven of

\footnotetext{
* Shagufta Nasreen, Ph.D. Assistant Professor, Centre of Excellence for Women's Studies, University of Karachi, Karachi

** Asma Manzoor, Ph.D. Assistant Professor, Centre of Excellence for Women's Studies, University of Karachi, Karachi
} 
the ten most populous cities of the world are in the Asia-Pacific region ${ }^{1}$. What is especially significant is the increase in short-term and circular activities which include a variety of activities from excursions that last several months, to daily traveling for work. The overall effect is that while more individuals are moving completely out of non-urban places to towns, a lot more individuals are also moving momentarily or distributing between towns and other places. ${ }^{2}$ Circular migration seems to be growing as the prominent design of activity of lesser categories who keep one foot in the town either by basic need or choice. According to United Nations it is not possible to adopt one definition to distinguish between urban and rural areas. ${ }^{3}$ World Bank also defines that urban and rural areas vary from country to country depending on their administrative boundaries, size, level of services or population density. ${ }^{4}$

As compared to Pakistan statistical yearbook 2011 which showed that the population of Pakistan is 177 million with a natural growth rate of 1.8 percent and according to the demographics of Pakistan estimated population in 2015 is over 191.71 million making it the world's sixth most populous country in the world ${ }^{5}$. Table- 1 shows mark increase in urban population.

\section{Table-1}

\begin{tabular}{|l|r|r|r|}
\hline Selected Demographic Indicators & \multicolumn{1}{|c|}{$\mathbf{2 0 1 3}$} & \multicolumn{1}{|c|}{$\mathbf{2 0 1 4}$} & \multicolumn{1}{c|}{$\mathbf{2 0 1 5}$} \\
\hline Total Population (Million) & 184.35 & 188.02 & 191.21 \\
\hline Urban Population (Million) & 69.87 & 72.50 & 75.19 \\
\hline Rural Population (Million) & 114.48 & 115.52 & 116.52 \\
\hline
\end{tabular}

A study published by PIDE reveals that about $63 \%$ moved to an urban area in the last ten years and out of that, majority (56\%) migrated to the major cities or capital cities. ${ }^{6}$

There are some broad patterns which characterize internal migration within developing countries. Rural-to-urban migration has dominated both policy concerns and economic analysis. Migration of people may take many forms such as moving to an urban area, nomadic wanderings, travel to work, visiting relatives or friends, or migrating between regions. Studies show that census and sample survey data normally report only a limited range of migrant population with some limitations of full mobility histories. ${ }^{7}$ Mainly as a

\footnotetext{
1 ESCAP, "Urbanization Trends in Asia and the Pacific,"(2013), Accessed on 16 March, 2017 from www.unescapsdd.org/files/ documents/SPPS-Factsheet-urbanization-v5.pdf .

${ }^{2}$ World Bank, "World Bank Indicators Online," (Washington DC. USA: World Bank, 2007).

${ }^{3}$ United Nations, "World Urbanization Prospects: Revision, Department of Economics and Social Affairs, 2003" (New York: Population Division, UN, 2004).

${ }^{4}$ World Bank, "World Bank Report 2009: Reshaping Economy Geography,"(Washington DC: World Bank, 2008).

${ }^{5}$ Government of Pakistan, "Pakistan Economic survey (2014-15)" Accessed on 16 March, 2017 from http://www.finance.gov.pk/survey/chapters_15/12_Population.pdf

${ }^{6}$ Mahmud, Mahreen, Tareena Mussadiq, and Farah Said, "Internal Migration Patterns in Pakistan- The Case for Fiscal Decentralization,” Pakistan Dvelopment Review, 49:4 Part II (Winter 2010) 593-607.

${ }^{7}$ Lucas, Robert. E.B. "International Migration and Economic Development: Lessons from Low-Income Countries" (Cheltenhan: E.Elgar, 2008).
} 
result of lack of informative data the tendency of internal migration has not been comprehensively researched in Pakistan. The last inhabitants' demographics were performed in 1998. Similar findings are revealed by M. Arif ${ }^{8}$ combining the details of demographics with the Pakistan Socio-Economic Survey, 2001. The study shows that approximately $40 \%$ of the migrations are rural to urban and mostly males $(60 \%)$ report financial factors for migrating, whereas for females it was family related such as wedding. The trend was different for rural-urban migrants who were relatively younger and more educated as compared to rural-rural migrants. ${ }^{9}$ In this study the focus is on identifying reasons of migration from rural to urban areas in search of better opportunities for work, the kind of housing facilities they face in urban katchi abadis and its impact on women. Population of Karachi has increased many folds as compared to the 1998 census which reported that there were 9.9 million residents in Karachi while the urban resource centre reports that in 2020 population will be 27.5 million and likely to increase 37 million in 2030 and the major contributing factor is rural to urban migration. ${ }^{10}$

\section{Research Question}

The research questions include:

- What are the reasons of migration of women from rural to urban areas of Pakistan?

- What kind of problems they face after living in a katchi abadi?

\section{Review of Literature}

Migration is taking place at both national and International level. The demand for workers in capital - rich but labor-short countries increased rate of migration after 1970s. Migration takes place within country and across national borders. The demographic and socioeconomic profiles have important implications for development. They affect the labour market, population structure and provision of services. According to the 2013 World Migration Report Internal Migration is defined as "a movement of people from one area of a country to another for the purpose or with the effect of establishing a new residence. This migration may be temporary or permanent. Internal migrants move but remain within their country of origin (as in the case of rural to urban migration)" ${ }^{11}$. The report shows that migration remains predominantly low-skilled due to which they usually end up in informal sector jobs.

\footnotetext{
${ }^{8}$ Arif, G.M. "Internal Migration and Household Wellbeing: Myth or reality," IDE Discussion Papers 72 (Institute of Developing Economies, 2005).

${ }^{9}$ Mahmud, Op.cit.

${ }^{10}$ Nakhoda, Aadil, "Rural to urban areas: Migration increases with drop in agri-income levels,"The Express

Tribune, (August 28, 2016), Accessed on 10 September, 2016, from https://tribune.com.pk/story/

1171496/rural-urban-areas-migration-increases-drop-agri-income-levels/.

${ }^{11}$ World Migration Report, "International Organization for Migration (IOM), (2013) Accessed on $3^{\text {rd }}$ March, 2014 from publications.iom.int/bookstore/free/WMR 2013_EN.pdf, 65
} 
Pakistan is facing both types of migration i.e. within country and outside the country. In Pakistan, rural-urban migration seems to be a very common problem. According to statistics, migration has increased from $52.87 \%$ to $63.60 \%$ during the period of $1981-$ 1998 censuses. ${ }^{12}$ The influx of migration seems to be focused to move urban cities like Karachi, Lahore, and Rawalpindi. Researchers identify different reasons related to migration such as the limitation of data to explain the relationship between migration and development. ${ }^{13}$ Karachi being the largest metropolitan centre of the country has the highest number of in-migrants as a proportion of its inhabitants. At a disaggregated level, it also covers the record for migrants from rural areas inspired to shift due to economic reasons. ${ }^{14}$ Most of the people migrating due to economic pressures end up living in urban slums called "katchi abadis". Memon" in his research explores that rural-urban migration is not seen as a positive trend by policy makers due to the implied strain on urban infrastructure and housing. Despite the importance, urban planning faces many challenges in Pakistan. It seems that a laissez-faire policy has been adopted for access to services, such as residential land and water. For instance the issue of housing is of prime importance since migration has given rise to a large number of irregular settlements known as katchi abadis. These Katchi Abadis usually develop on government and private lands through illegal land occupation. Later the temporary structure begins to take more permanent shape. The general living conditions in these areas are dismal, insanitary and stagnant. $^{16}$

\section{Gender and Migration}

Migration of people is a key aspect of globalization and it is necessary to analyze it from gender perspective. Internationally, the number of women migrants has increased including international and national level migrants. Usually women migrate in large numbers on their own, but many women migrate or join their relatives.

Usually women migrate in large numbers on their own, but many women migrate or join their relatives. Women, not only earn to fulfill their own needs but they are the chief wage earners of their families as well. Though women have their own reasons for migration but a large number of them are forced to migrate for several reasons like environmental hazards, natural disasters, tribal or war conflicts, discrimination and harassment, calamities and situations which directly affect their living environment and income. $^{17}$

\footnotetext{
${ }^{12}$ Government of Pakistan, “1998 Census report of Pakistan,” (Pakistan Census Organization (PCO), 2002).

${ }^{13}$ Tahir, Pervez, \& Lubna Shahnaz, "Background Information and Some Analysis of Migration," Paper for Regional Conference on Migration, Development and Pro-Poor Policy Choices in Asia (Dhaka, 22-24 June, 2003).

${ }^{14}$ Nakhoda, Op.cit.

${ }^{15}$ Memon, R. "Pakistan: Internal Migration and Poverty Reduction," Collective for Social Science Research, (Karachi, 2005) Accessed on 3 January, 2016 from http://www.researchcollective.org/Documents/ Rashid_Memon_migration_paper.pdf

${ }^{16}$ UNICEF, "Situation Analysis of Women and Children in Sindh," (Govt. of Sindh \& UNICEF,1993).

${ }^{17}$ Martin, Susan Forbes, "Consultative Meeting on Migration and Mobility and How This Movement Affects Women United Nations Division for the Advancement of Women" (2003) Accessed on 12 August, 2016 from www.un.org/womenwatch/daw/ meetings/ consult/CM-Dec03-WP1.pdf.
} 
According to the analysis of 1998 census, in $198145.66 \%$ female migrants' ratio is raised to $48.96 \%$. These statistics shows that women migrate mainly after marriage with their spouse in order to gain income generation opportunities to feed their families. As per facts by PIHS calculations for the year 1998/99, out of all the given calculations the highest number that is $(47.5 \%)$ women migrants are unpaid family helpers, whereas $(28.4 \%)$ are employees and (23.6\%) women are self-employed. ${ }^{18}$

Economic and Social Commission (ESCAP) ${ }^{19}$ identified that export-oriented industries are boosted and pushed by foreign investment by creating employment opportunities in different sectors for young women like textile and apparel, electric equipment and gadget. This trend is growing more and more for young unmarried women, to seek industrial urban zones in order to support their parents. Another motive of seeking job in urban areas for these women is to earn money to send home and to save for them with an objective to go back to their town to get married, which clearly shows they adopt such kind of jobs temporarily. ${ }^{20}$ The trend is common in the South American and African region. A study was conducted in the Export Processing Zones in Karachi in which it was confirmed that young, unmarried females' workers were preferred for these jobs. ${ }^{21}$

Thapan in an article identifies an interesting fact about migration that the process of migration has many aspects leaving behind the familiar world, exploration of the new world. ${ }^{22}$ Therefore, it gives one a less choice made available including exploitation, abuse leading to socio-economic and psychological stress. Migration is often perceived as being mainly a male movement, with women either left behind or following their men folk. In situations where women are left behind in rural areas, female headed households are created. Women are left to take over tasks beyond their traditionally defined responsibilities, as men migrate. In other cases when women migrate along with their families, they encounter problems in urban areas, mainly adjusting in a new location and lack of basic facilities such as water and sanitation. However, there is another feature of migration. It is also noticed that improving the status of women through increased access to reproductive health care in rural and urban areas can impact migration and urbanization tendencies by decreasing requirement for public services and increasing job and economic opportunities. ${ }^{23}$ In many countries, remittances are very effective at reducing poverty in the family members of those who have moved, and, to a smaller level, in their surrounding communities. Some studies show that migration impact positively on the status of women. In rural Pakistan, where girls are usually

\footnotetext{
${ }^{18}$ Mumtaz, Khawar, "Pakistan Poverty Assesment Update: Background Paper Series" Asia Development Bank (2006).

${ }^{19}$ ESCAP. “Migration, Urbanization and Poverty: Urbanization and Internal Migration," Paper presented in Fifth Asian and Pacific Population Conference, Senior Officials Segment - Bangkok:Sept.19,2002, Accessed on 16 February, 2014 from http://www.popline.org/node/ 246006\#sthash.2LDhrFTR.dpuf (2002).

${ }^{20}$ ESCAP, Op.cit.

${ }^{21}$ Manzoor, Asma, “'Labour Laws ana Women Workers of the Export Processing Zones in Karachi” Pakistan Journal of Gender Studies, 7, (2013) 1-16.

${ }^{22}$ Thapan, Mennakshi, "Women and Migration in Asia," Arya, S. \& Roy, A. Poverty, Gender and Migration (New Delhi: Sage, 2006) 8-17.

${ }^{23} \mathrm{UN}$, "Demographic Revolution Under Way Brings Challenges, Opportunities for Sustainable Growth ( ${ }^{\text {rd }}$ April 2017) Accessed on 2 July, 2017 from https://www.un.org/press/en/2017/pop1054.doc.htm.
} 
underrepresented in school enrollment rates, girls from migrant houses are healthier, more likely to stay in school, and are less likely to be sent to work. ${ }^{24}$ Researches show that chances of migrant girls for seeking health facilities and services utilization increases as compared to girls of rural areas. ${ }^{25}$ But this situation depends on urban environment in which they get settled. The availability of services and affordability depends on the new environment which they adopt in order to achieve economic and socio-cultural benefits.

Along with that they mostly depend on traditional child birth practices. Distance to health facility and cost of seeking health-care was a major constraint observed. Nevertheless this may not be the case for all who migrate from a rural to an urban area. ${ }^{26}$

Another aspect linked to migration is that it is divided into legal and illegal migration. Usually, the census document legal migration ${ }^{27}$. However, human trafficking cannot be ignored in this regard. People may choose voluntarily to migrate or may be deceived about the kind of work they are subsequently expected to do. ${ }^{28}$ Trafficking and illegal migration is out of the scope of this research.

\section{Migration and Poverty}

Migration and poverty has a relationship of cause and effect. It can be alleviated as well as exacerbated by population movement. Poverty is measured in absolute and relative terms. Absolute poverty defines a minimum standard of living based on a person's biological needs for food, water, clothing and shelter. Relative poverty compares the standard of living of low income groups with better income groups within a society. Relative approaches view poverty as a social construction, based on the belief that a certain standard of living is desirable for everyone in a given society at a given time. ${ }^{29}$

There are different factors playing important role to understand this relative impact such as variation in the level of development of the area under consideration ${ }^{30}$. Skeldon explores some interesting patterns related to migration in relation to poverty. In some cases poverty is the cause while in others poor are the last to move from a poverty ridden place. In the countries of Asia and the Pacific during the 1990 s, poverty appears to have

\footnotetext{
${ }^{24}$ Population Action,"Why Population matters to migration and urbanization" (2011) Accessed on 2 December, 2015 from http://populationaction.org/policy-briefs/migration-and-urbanization/.

${ }^{25}$ The World Bank, "World Development Indicators," (2013) Accessed on 2 December, 2015 from http://databank. worldbank. org/ data/download/WDI-2013-ebook.pdf.

${ }^{26}$ Stephenson, Rob \& Matthews, Zoe, "Maternal Health-Care Service Use among Rural-Urban Migrants in Mumbai, India” Asia- Pacific Population Journal, 19, No.1 (2004) 39-50.

${ }^{27}$ Datta, Pranati, "Female Trafficking and Illegal Migration from Bangladesh to India," Pakistan Journal of Gender Studies: Alam-e-Niswan, 18, No.1 (Karachi, 2011).

${ }^{28}$ Ali, Salma, "Sustainable Development: Bridging the Research/ Policy Gaps in Southern Contexts," Vol.2, SDPI (Oxford, Islamabad, 2005).

${ }^{29}$ Kane, Sharon, and Mark Kirby, "Wealth, Poverty and Welfare" ( New York: Plgrave, 2003).

${ }^{30}$ Skeldon, Ronald, "African Migration and Urbanization in Comparative Perspective, Johannesburg, South Africa," (2003) Accessed on 13 August, 2013 from http://time.dufe.edu.cn/ wencong/africanmigration/6 Skeldon.pdf.
} 
declined in Bangladesh, India, China, the Philippines and Thailand but increased in Pakistan, Sri Lanka and throughout the new republics of Central Asia. ${ }^{31}$

\section{Methodology}

Data was obtained using mixed method approach comprising structured interviews based on open and closed ended questions interview schedule. The target population was women living in katchi abadis of Karachi who have migrated from rural areas. The sample included 100 married women selected by purposive sampling method in four squatter settlements selected through convenient sampling for this research namely Yaseen Goth (Ayesha manzil), Juma Goth (Nipa), Landhi and Gulshan-e-Iqbal. During interviews women willing to share their life stories were selected for Case studies. Simple tabular analysis was used to draw meaningful. Few tables are mentioned in text due to limited space while other details are discussed with reference to the interviews conducted during research.

\section{Results and Discussion}

In search of improving their standard of living people usually move from one place to another. The phenomenon is not new but growing population and unequal distribution of resources has triggered this process many folds. As already discussed in review of literature migration is considered to improve the living standards of the common people. On the contrary, research also shows that the outcome is not the same for all. Memon identifies a gap in research and policy with reference to internal migration although it is very important to address. ${ }^{32}$ There is sufficient empirical evidence about migration and it's demographics but they ignore expansion of welfare induced by the economic and social aspect of migration. According to UNESCO report migrants are excluded from the economic, cultural, social and political lives of society. It highlights many challenges faced by migrants such as residence, lack of political representation, low-paid jobs and temporary work, and discrimination faced due to ethnicity, religion, class or sexual orientation. Children accompanying migrating families face disruption of regular and continued schooling, adversely affecting their human capital formation and contributing to the inter-generational transmission of poverty. ${ }^{33}$

The present study explores the reasons of women migrants coming to an urban area and the conditions in which they are living. Majority of these women were illiterate. Most of them were married having 6 children on average and they are all living in joint family system. Table-1 show that most of them started living in a kacthi abadi recently, however, some of them were living there for a long time.

\footnotetext{
${ }^{31}$ Ibid.

${ }^{32}$ Memon, Op.cit.

${ }^{33}$ UNESCO, "Internal Migration" (2011) Accessed on 13 August, 2013 from

http://www.unesco.org/new/en/newdelhi/areas-of action/ social-and-human-sciences/internal-migration/.
} 
Table -1

Distribution of respondents according to the time from which they have been living in squatter settlement

\begin{tabular}{|l|c|c|}
\hline Duration & Frequency & Percentage \\
\hline Less than one year & 60 & $60 \%$ \\
\hline $1-2$ years & 20 & $20 \%$ \\
\hline $2-3$ years & 20 & $20 \%$ \\
\hline Total & 100 & $100 \%$ \\
\hline
\end{tabular}

Majority of them moved from their village to city due to poverty. Some respondents identified in case studies that they were living in better environmental conditions earlier. But when they moved to an urban area they did not find the facilities they perceived they would get. Primary data shows that people living in rural areas are usually attracted by the facilities available in urban areas such as availability of electricity, water supply, transport, and job opportunities. However, they are unaware of the fact that by moving to a city they would not be able to avail all the facilities just by moving to an urban area. Rather they find a living place in a katchi abadi at a low cost with no sanitation and drinking water facilities. This usually results in increase of pollution affecting the lives of their family and the neighborhood. To get water, they have to go too far off areas, nearby houses or often break the main lines of water making pools of stagnant water in many places, causing a damage to the infrastructure and wastage of resource. The broken water lines become a source of supply line of contaminated water to the community. Most of these women complained about diseases caused by polluted water.

Table - 2

Distribution of the respondents according to reasons of coming to an urban area

\begin{tabular}{|l|c|c|}
\hline Reasons & Frequency & Percentage \\
\hline Poverty & 50 & $50 \%$ \\
\hline For improving standard of living & 35 & $35 \%$ \\
\hline In search of employment & 15 & $15 \%$ \\
\hline Total & 100 & $100 \%$ \\
\hline
\end{tabular}

Several factors were identified leading to internal migration, such as poverty, urbanization and search for improvement in standard of living. During interviews most of them said that they are doing work as domestic help in the homes near their katchi abadi. This study confirms the study of Agrawal $^{34}$ who identifies economic factor as a significant role in driving the migration process. Further she explains that class position is also a cross cutting feature. Domestic workers are particularly vulnerable segment of

${ }^{34}$ Agrawal, Anuja, “Introduction: Women, Work and Migration in Asia," Women and Migration in Asia, 4, ed, Anuja Agarwal (New Delhi: Sage, 2006) 21-45. 
migrant women given that their conditions are extremely isolating which do not allow any kind of organizational benefits to their class.

Table -3

Distribution of the respondents according to satisfaction in urban area

\begin{tabular}{|l|c|c|}
\hline Satisfied after coming to urban area & Frequency & Percentage \\
\hline Yes & 65 & $65 \%$ \\
\hline No & 35 & $35 \%$ \\
\hline Total & 100 & $100 \%$ \\
\hline
\end{tabular}

Table 3 shows that $65 \%$ of these women showed satisfaction after their migration from a rural to an urban area but they also shared problems faced by them in urban areas. During interviews when they were asked about the condition of their home, 92 percent showed dissatisfaction due to poor economic condition and inflation.

The major problem they identified was lack of electricity and gas. As discussed earlier in this section they are ignorant of the fact that when cities are planned, these facilities are provided according to the needs of residential areas. As a result they get involved in theft of electricity.

Table -4

Distribution of respondents according to problems facing in squatter settlement

\begin{tabular}{|l|c|c|}
\hline Problems faced & Frequency & Percentage \\
\hline Electricity and Gas connection & 44 & $44 \%$ \\
\hline Less opportunities of jobs & 33 & $33 \%$ \\
\hline Sanitation problem & 14 & $14 \%$ \\
\hline Lack of education facilities & 09 & $9 \%$ \\
\hline Total & $\mathbf{1 0 0}$ & $\mathbf{1 0 0 \%}$ \\
\hline
\end{tabular}

A few case studies were included in this study to provide a better understanding of the lived realities of migrant women. Talking about their life stories gives them a liberty to express their feelings and experiences and this in turn helps the researcher to understand the uniqueness of each story.

\section{Case study}

Naseem is married and has five children, three boys and two girls. She belongs to Swat, Khyber Pakhtoonkhwah (KP). They used to grow vegetables in their native town. They were growing enough vegetables but did not have transport facilities in their village so that they could market them to urban areas. Her village was lacking educational and 
health facilities and they had to go to the city for treatments. Apart from that they had clean water and nutritional food available all the time. To improve their standard of living, they came to Karachi two years back. When they came to Karachi they had no place to live. They found a katchi abadi and started living in a tent. Before coming to the city they thought when they will come to Karachi, their standard of living will improve but it never happened. They faced lack of basic necessities and their children started suffering from stomach problems. They started looking for work. Her husband is working on daily wages and his average daily income is Rs.250/- per day. To support him she started working as a domestic help in nearby houses at Rs.900/- per month. This has helped in their basic survival. Her family is surviving with great difficulty. She wants to spend her income on her children's education but it is difficult to meet their needs.

Shamim's family lives nearby and she is a mother of 10 children, five boys and five girls. She also migrated from Swat and has been living here for the last ten years. The major reason of migration was poverty. They came here with high hopes of improving their standard of living but her husband is uneducated and has no technical skills or experience. Therefore, he works on daily wages. Due to malnutrition her family is facing health problems. Usually when they visit doctors the behavior of doctors is also not good. She is unable to engage in paid activities because of her weak health condition.

In the same community a young girl named Zehra, came to Karachi after marriage shared her experience. Both husband and wife were uneducated. She got pregnant after few months and went to hospital for routine checkup. The doctor suggested some tests but she was afraid of them because she thought they will be painful to do so. Along with that she could not afford their cost. At last she delivered her baby in her tent. The baby was born but died within three days. They accepted it as will of God and because for her it was normal to deliver babies at home and she had no complain about it. Later, her health got deteriorated due to which she was hospitalized and was diagnosed anemic which was the major cause of her baby's death.

The cases narrated above show common factor of migration i.e. poverty and lack of facilities in rural areas. Secondly, they are facing severe health problems due to living in a katchi abadi. Moreover, paid jobs, in which these men and women are engaged, have not brought any significant change in the living standard because whatever they earn is so low that they hardly manage to fulfill their basic requirement of life.

\section{Conclusion}

The study shows that migration from rural to urban areas is increasing due to poverty however it is not given much importance in poverty reduction strategies. Firstly, the need is to identify the rate of internal migration and create a policy according to internal mobility, job acquisition, housing and associated families. The need is to plan the development projects in such a way that urbanization should not increase at such a faster rate. The number of women in urban areas is increasing due to migration from countryside. Consequently, they live in the poor, urban squatter settlements, located on 
unsuitable land with lack of sanitation facilities and in some cases close to potential industrial hazards. Although this study was conducted with women moving to an urban area due to poverty, displacement due to natural disasters may also be the cause of faster pace of migration. Statistics shows-an increase in poverty especially in females. This situation is common in developing countries where poverty, illiteracy, limited access to control over resources marginalize women. Although on International and National level, commitments have been made to change this situation but the results are not satisfactory. The need is to take decisions that promote equity and social justice. The distribution of resources and development planning need to focus on the needs of urban and rural areas on equal bases because just moving to a city is not changing the condition of the lives of people; it is rather deteriorating the situation. 